\title{
Innovations in Ophthalmology Education: a Particular Instantiation of General Principles
}

\author{
Phillip X. Braun ${ }^{1,2}$ • John Encandela ${ }^{3,4}$ - Ninani Kombo ${ }^{5}$
}

Accepted: 6 November 2020 / Published online: 20 November 2020

(C) International Association of Medical Science Educators 2020

\section{Introduction: The Lecture in Crisis?}

On arrival at medical school in 2015, one of the authors (PXB) quickly became acquainted with the challenge of digesting vast quantities of information in a limited amount of timepopularly analogized as "drinking from a fire hydrant with a straw." While a newly revised curriculum had placed increased emphasis on the flipped classroom as well as reorganization of content, lectures remained a key mode of information delivery, as is the case at most medical schools. In the learner's (PXB) view, the effectiveness of the standard medical school lecture - whether in vivo or recorded - warrants reevaluation in at least a few respects.

First, lecturers would do well to reconsider how they approach the "fire hydrant" problem. Regardless of whether lecturers historically had enough time to address content adequately-medical knowledge, and therefore medical school subject-matter, has only increased with the passing years - this is a great challenge in our current time, and even more so due to the abridgement of the pre-clinical curriculum at many medical schools in the twenty-first century [1]. With a decreasing amount of time to cover material and an increasing amount of material to cover - in addition to any longstanding pressures associated with imparting knowledge of medicine

Phillip X. Braun

phillip_braun@urmc.rochester.edu

1 Flaum Eye Institute, University of Rochester Medical Center, Rochester, NY, USA

2 Yale School of Medicine, New Haven, CT, USA

3 Department of Psychiatry, Yale School of Medicine, New Haven, CT, USA

4 Teaching and Learning Center, Yale School of Medicine, New Haven, CT, USA

5 Department of Ophthalmology and Visual Science, Yale School of Medicine, New Haven, CT, USA through lecture-based courses - it is unsurprising that the traditional lecture format is strained. It is not uncommon to come across 60 or more densely informational PowerPoint slides during a 50-minute lecture, and to have four such lectures delivered consecutively. This is far from ideal for digestion of content, to say nothing of thorough comprehension and retention.

Second, lectures may be taught by excellent clinicians and pioneering scientists, but it is not always the case that they are taught by good educators and communicators. This could reflect institutional priorities (patient care and research before education), inertia (e.g., implicit or explicit priorities that are inherited, or perpetuating "the way it's always been done"), or economics (by comparison with the clinic or the laboratory, educational reimbursement for the medical school lecturer may be trifling, if reimbursement is provided at all [2]). Nonetheless, it would be strange to ask someone with excellent teaching abilities to perform clinical duties with minimal clinical knowledge or skills; strange too, then, to expect an expert clinician to teach well without proper knowledge or skills. Demonstrating academic ability through research, publication, and sound clinical judgment does not thereby guarantee teaching prowess.

For such reasons, it may be the case that lectures come at a substantial opportunity cost. The information age, brought about by modern technologies such as the internet, powerful search engines, and mobile devices, has in essence expanded the academic "marketplace": where transmission of pre-clinical knowledge was once confined to medical school lecture halls and libraries, medical students now have much greater choice with respect to educational resources, including access to some of the finest medical educators and communicators in the world through online courses, videos, and podcasts, in addition to popular textbooks and review books. Medical students have limited time to learn a set amount of content, and so it behooves them to learn in the most efficient and effective way possible. If students find alternative resources superior to their lecturebased curricula in this regard, it is very reasonable for them to 
favor these resources. In this case, the lecture faces something like an existential crisis. How can lecturers of varying skill compete with some of the world's finest medical educators, accessible through digital and other media? What if, for some students, lectures are more of a hindrance than a help in their overall study program? For those medical students preferring alternative resources to lecture-based learning, what is the lecture for?

\section{Some Proposals}

While the lecture format as a means of teaching in medical school certainly has the weight of tradition behind it, education ought never be pro forma, and should, through frequent and dynamic feedback, use its allotted time as effectively as possible. We do not think lectures are without a place in medical education, but they may need to be substantially reconceived.

First, pre-clinical educators and curriculum administrators should familiarize themselves with extra-institutional learning resources and their efficacy with respect to core pre-clinical competencies. These resources and institutional instruction should not be seen as competitors but rather complementary and synergistic. For instance, in lieu of a slide-dense lecture on the pathophysiology of chronic obstructive pulmonary disease, a lecturer might refer, either as preparation material or in-class, to an excellent, economical explanation found in an online resource. Having thus well and efficiently presented a core concept, the lecturer could address any material thought to be too oversimplified, provide any clarification and additional relevant details, and have adequate time for questions. This approach is consistent with the "curate versus create" paradigm, which involves using existing, high-quality resources rather than "reinventing the wheel"-perhaps at somewhat lower quality — while potentially saving the educator preparation time [3].

Microlectures or "mini" lectures have been advocated in great detail elsewhere, popularized through ubiquitous TED talks, and promoted through the online Khan Academy [4, 5]. The essence of microlectures is the delivery of "bite-sized nuggets" of digestible information in time periods better aligned with learner attention spans (a well-known study concluded that a typical medical student's attention span tends to fade after ten minutes of lecture [6]). We support the further integration of microlectures into standard lecture blocks as we think it generally more productive to focus instruction on communication and retention of core concepts, rather than hurried attempts at more exhaustive coverage of content which may result in reduced absorption and retention of material. Ancillary or derivative material can be learned outside of the classroom based on resources curated by the educator.
Medical school lectures could also take inspiration from lectures in the humanities, with which one of the authors (PXB) has considerable experience. Especially in a liberal arts setting, lecture-based teaching tends to be prioritized highly, and fine educators are esteemed. As has been observed of good literature from the Roman poets Lucretius and Horace to the medieval author Chaucer, good humanities lectures both "instruct and entertain" [7-9]. In many cases, there is nothing essential to be gained from a lecture - all required knowledge may be found in primary and secondary texts - and yet, despite this, lectures are popular because of the instructor's teaching ability, enthusiasm, and unique critical perspective. Good humanities lectures often have a theatrical or performative element. Admittedly, it is probably the case that the aims of the humanities conduce more naturally to this manner of teaching; if, for instance, the only competencies tested in a literature course involve demonstration of a student's own thoughtful analysis of certain texts, an educator is free to lecture on aspects of these texts that are, strictly speaking, optional knowledge. This reflects the humanities' greater inclination towards non-utility-which is to say, beyond any use for intellectual, moral, or aesthetic (in)formation, they may be pursued as good in themselves, for their own sake. Medicine is decidedly a more utility-based pursuit, as learning significant quantities of information is critical for the purpose of competent patient care. Thus, as far as competencies are concerned, humanities lecturers are generally less constrained by the need to cover a great deal of indispensable material, and more free to develop an engaging presentation through interpretive license with respect to generally more subjective content.

Nonetheless, this does not mean that medical school lectures cannot incorporate elements of "instruct and entertain" and the performative. Lecturer enthusiasm is consistently cited as a key factor in effective teaching, and entertainment value has been associated with deeper learning and improved recall [10-12]. Restructuring of lectures as suggested above should permit more space for these elements. Curriculum administrators could consider identifying exceptional teachers (e.g., through annual student feedback) in each preclinical module (e.g., psychiatry) and invite them to teach the majority of that module. The aforementioned structural barriers to deploying the best educators and communicators in this way, such as institutional inertia or the economics of appropriate compensation for skilled teaching, may admittedly be a substantial challenge. Some medical schools have shown potential in this direction; for instance, our own home institution (Yale School of Medicine) has developed an academic track dedicated to clinician-educators. Finally, faculty interested in becoming more adept at designing and delivering engaging lectures should be offered a forum for doing so, perhaps led by the identified expert educators. 


\section{Innovations in Ophthalmology Education: a Pilot Project}

Keeping in mind the above proposals, during the academic year 2019-2020, we designed and implemented modifications to our institution's pre-clinical ophthalmology module. Ophthalmology was chosen because two of the authors (PXB, NK) were affiliated with the field. The involvement of one of these authors (NK), who was also the director of ophthalmology education for medical students, enabled rapid curricular change. Ophthalmology was also thought to be ideal for trialing interventions due to its limited presence in the curriculum (four days each containing at least one ophthalmology lecture). These interventions included the following:

(1) Recruitment of a student liaison who worked with the module director to provide frequent and dynamic feedback.

(2) The review, by a committee of three interested medical students who were also prospective ophthalmology residency applicants, of most PowerPoint slides that would be presented in the ophthalmology module. Students also had access to recordings of lectures from the previous year. Slide-by-slide edits and suggestions were made with stress placed on what learners felt would be most effective. In particular, more emphasis was given to the nature of ophthalmology as a surgical subspecialty, since one learner (PXB) felt students might complete the module conceiving of ophthalmology more in terms of "phoropters and eyedrops," without appropriate appreciation of procedures and surgery. Extensive, curated reference was therefore made to existing online resources and videos discussing and demonstrating key aspects of these interventions.

(3) The reconceptualization of two standard lectures on the topic of "the red eye." These were each re-presented as microlectures. Recognizing that the vast majority of students would not be pursuing ophthalmology as a subspecialty - but not wishing to compromise quality information for those who would - and also hoping to emphasize understanding and retention of the most fundamental competencies, we chose as the "bite-sized nugget" and organizational principle of these microlectures the distinction between cases of red-eye that were visionthreatening versus those that were not. The first microlecture began with a review of eye anatomy, with a superficial-to-deep analysis of how an ophthalmologist would record findings. Brief, basic review questions were included for engagement and reinforcement. It was then acknowledged that causes of red eye were numerous and ranged from common to obscure, but that what was critical for all learners to know was how to differentiate between emergent versus non-emergent causes of red eye, which was in turn strongly predicated on the presence or absence of pain. A parallel superficialto-deep analysis of "painless" red-eye conditions that could arise at each anatomical level was subsequently discussed. The second, immediately following microlecture began with review cases for "painless" red-eye conditions, again for engagement and reinforcement. "Painful" red-eye conditions by anatomic level were then described (example slide shown in Fig. 1). The microlecture concluded with review cases for the "painful" red-eye conditions just discussed, as well as review cases combining a mixture of "painless" and "painful" pathologies, with each analysis beginning with the question, "Are we worried about this eye?" (Fig. 2)

(4) Three months following the ophthalmology module, one of the authors (NK) teamed up with a member of another department who had expertise in microlectures to deliver a presentation on microlectures to interested faculty across the medical school.

\section{Discussion and Directions}

Anecdotally, one of the instructors and authors (NK) noted particular enthusiasm with respect to referencing online resources and videos during the student-reviewed lectures, with student engagement in part evidenced by an abundance of questions for the instructor. While we piloted an approach for evaluating lecture format efficacy following the second microlecture, during the module's next iteration, we anticipate conducting a full evaluation to explore both microlecture efficacy and long-term concept retention. We note, again anecdotally, that response to the co-taught microlecture seminar for interested faculty (intervention 4 , above) was very positive, with faculty from multiple disciplines expressing interest in the format, and in improving their teaching skills.

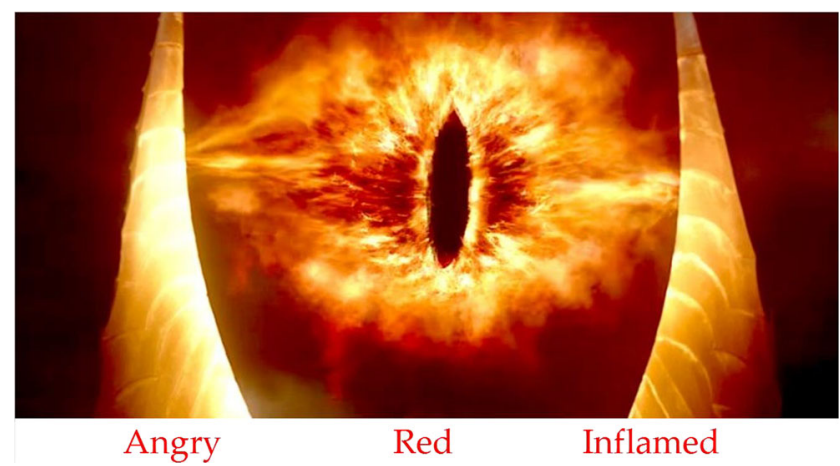

Fig. 1 PowerPoint slide using a popular cultural reference to provide an entertaining mnemonic for uveitis (image credit: New Line Cinema) 
Integrated/review case 1

- A 36-year old woman was in the restroom and noticed the findings in the accompanying image. She has a hx of SLE and says she is getting over a cold with coughs, sneezing, and a runny nose. During the cold, she thinks her eyes have been more watery than usual, but the eye is not itchy or painful. She is a contact lens wearer with BCVA $20 / 20$.

- Are we worried about this eye?

- Most likely diagnosis?

Fig. 2 Example PowerPoint review slide testing organizational principle of and recently imparted information from red-eye microlecture (image credit: eyecenters.com)

Based on qualitative data, we think our interventions were generally successful, and both faculty and learner enthusiasm were evident. This paper has attempted to present an analysis of pressing issues that cut across all disciplines in medical education, and demonstrate how these issues might begin to be addressed in a particular case. Our interventions are a work-inprogress, a starting point for further refinement and hopefully broader application in disciplines beyond ophthalmology.

\section{Key Points}

$>$ Frequent and dynamic feedback among students and instructors regarding the effective use of time allotted for education

$\gg$ A complementary rather than competitive understanding of traditional and information-age resources

$>$ Content curation instead of creation can result in higher-quality, more efficiently produced material

$>$ Microlectures focus on imparting and retaining core concepts; along with curated ancillary material, this represents one possible response to the challenge of a vast and expanding amount of content

$\gg$ Humanities-style lecturing has much to offer the medical school lecture, viz., an emphasis on entertaining instruction, as well as the engaging, enthusiastic, performative delivery, and the emphasis on the lecture as a unique and important learning experience

$>$ The most capable teachers should be invited to teach the majority of modules, and infrastructural changes, such as a clinician-educator track, should be implemented to support them

$\gg$ Institutional forums for the enhancement of teaching skill should exist for interested faculty

\section{Coda: An Opportune Time}

This paper was written during the COVID-19 pandemic, during which teaching at our institution-like many institutions of higher learning - became fully virtual. In our experience, insights for educators from this time of necessary adaption have been manifold. One of the authors (JE), who is involved in evaluation of the overall program of pre-clinical medical student education, noted the willingness and capability of faculty with respect to this virtual teaching. We also note that many students have been satisfied with virtual learning, based on recently administered course evaluations, and most have requested some kind of "hybrid" virtual/in-person approach to teaching even after safe return to campus is possible. Thus, one "silver lining" of the pandemic might be that some institutions have been forced to revisit their pedagogical approaches to medical education and explore new methods of instruction - including the online and virtual — which might make them more receptive to the expeditious adoption of approaches such as those recommended in this paper.

\section{Resources for Further Reading}

- Braume C (2013). Flipping the classroom. Vanderbilt University Center for Teaching. Retrieved on Sept 22, 2020 from http://cft.vanderbilt.edu/guides-sub-pages/ flipping-the-classroom/.

- Graffam B. Active learning in medical education: strategies for beginning implementation. Med Teach. 2007;29(1):38-42. https://doi.org/10.1080/ 01421590601176398 .

- Moffett J. Twelve tips for "flipping" the classroom. Med Teach. 2015;37(4):331-6. https://doi.org/10.3109/ 0142159X.2014.943710.

- Narang A, Velagapudi P, Rajagopalan B, LeBude B, Kithcart AP, Snipelisky D, et al. A new educational framework to improve lifelong learning for cardiologists. J Am Coll Cardiol. 2018;71(4):454-62. https://doi.org/ 10.1016/j.jacc.2017.11.045.

- Society of Hospital Medicine. Clinical quick talks: brief talks for medical educators in a number of disciplinespecific areas. Online resource. Retrieved on September 23, 2020 from https://www.hospitalmedicine.org/ professional-development/clinical-quick-talksoverview/.

- Team-Based Learning Collaborative. Retrieved on September 23, 2020 from http://www. teambasedlearning.org.

- MedEdPORTAL. Retrieved on October 3, 2020 from https://www.mededportal.org/.

Author Contributions PXB and NK are responsible for conceptualization of stated interventions; PXB, NK, and JE are responsible for design and implementation of interventions; $\mathrm{PXB}$ is responsible for initial drafting of the manuscript; JE and NK are responsible for manuscript review and commentary; all authors are responsible for reading and approving the final manuscript.

Data Availability Not applicable

\section{Compliance with Ethical Standards}

Conflict of Interest The authors declare that they have no conflict of interest.

Ethics Approval Not applicable 
Consent to Participate Not applicable

Consent for Publication Not applicable

Code Availability Not applicable

\section{References}

1. Emanuel EJ. The inevitable reimagining of medical education. JAMA. 2020;323(12):1127-8. https://doi.org/10.1001/jama.2020. 1227.

2. Brenner AM, Beresin EV, Coverdale JH, Louie AK, Balon R, Guerrero APS, et al. Time to teach: addressing the pressure on faculty time for education. Acad Psychiatry. 2018;42(1):5-10. https://doi.org/10.1007/s40596-017-0851-9.

3. Eduardo Viteri EM. Teaching through social media: the microlearning concept. American Academy of Ophthalmology Annual Meeting October 27; Chicago 2018.

4. Shieh D. These lectures are gone in 60 seconds. Chron High Educ. 2009;55(26):A1-A13.
5. Scagnoli N. 7 things you should know about microlectures. EDUCAUSE Learning Initiative. 2012. Accessed on 4/28/2020 at: https://library.educause.edu/resources/2012/11/7-things-youshould-know-about-microlectures.

6. Stuart J, Rutherford RJ. Medical student concentration during lectures. Lancet. 1978;2(8088):514-6. https://doi.org/10.1016/s01406736(78)92233-x.

7. Lucretius, De Rerum Natura 4.18-22.

8. Horace, Ars Poetica 343.

9. Chaucer, The Canterbury Tales General Prologue, 798-799.

10. Gifford H, Varatharaj A. The ELEPHANT criteria in medical education: can medical education be fun? Med Teach. 2010;32(3):1957. https://doi.org/10.3109/01421591003614866.

11. Burgess A, van Diggele C, Mellis C. Mentorship in the health professions: a review. Clin Teach. 2018;15(3):197-202. https:// doi.org/10.1111/tct.12756.

12. Mahler D, Grossschedl J, Harms U. Does motivation matter? - the relationship between teachers' self-efficacy and enthusiasm and students' performance. PLoS One. 2018;13(11):e0207252. https:// doi.org/10.1371/journal.pone.0207252.

Publisher's Note Springer Nature remains neutral with regard to jurisdictional claims in published maps and institutional affiliations. 